\title{
The effects of endometrial epithelium-derived exosomes on the recruitment and activation of T Lymphocytes in the uteri of dairy
} COWS

\author{
Hong $\mathrm{An}^{1}$, Bofan $\mathrm{Fu}^{1}$, Xinxin $\mathrm{Yao}^{1}$, Hemin $\mathrm{Ni}^{1}$, Yong $\mathrm{Guo}^{1}$, Longfei Xiao ${ }^{1}$, and xiangguo \\ wang $^{1}$ \\ ${ }^{1}$ Beijing University of Agriculture
}

July 16, 2020

\begin{abstract}
As a common group-occurring disease, endometritis is caused by endometrial cell injury and chronic inflammation of uteri infected by pathogenic microorganisms, and leads to reproductive failure in dairy cows. Changes in the immune response function of the uteri affect the occurrence and development of endometritis. It was recently discovered that exosomes act as a functional regulator secreted by a variety of cells. However, its regulatory mechanism in the local immune response of the uteri is still unclear. In this study, flow cytometry was adopted to identify that the number of T lymphocytes in the uteri with endometritis increased while the compositional proportion also changed, namely that of Tc cell increased very significantly and that of Th and Treg cells decreased very significantly. Moreover, the functional marker factor Foxp3 of Treg cells was extremely significantly decreased, and the functional marker factor of Th17 cells was significantly increased. The mRNA expression of immune tolerance regulators PD1, CTLA4 and Galectin-1 in the group of Treg cells which were co-incubated with LPSstimulated endometrial epithelium-derived exosomes was very significantly lower than in the group of Treg cells which were co-incubated with normal EEC-derived exosomes. Furthermore, the protein expression of PD1, CTLA4, Galectin-1, Foxp3, and IL-17 was consistent with the results in the Treg cells co-incubated with different source exosomes in mice. Therefore, it was demonstrated that endometrial epithelium-derived exosomes act as a vital regulator of changes in the composition and function of $\mathrm{T}$ lymphocyte subsets in the uterus of dairy cows.
\end{abstract}

\section{Title page}

The effects of endometrial epithelium-derived exosomes on the recruitment and activation of $\mathrm{T}$ Lymphocytes in the uteri of dairy cows

Running head: Exosomes activate T Lymphocytes

Hong An, Bofan Fu, Xinxin Yao, Hemin Ni, Yong Guo, Longfei Xiao*, Xiangguo Wang*

Animal Science and Technology College, Beijing University of Agriculture, Beijing 102206, China

*Corresponding author: Longfei Xiao and Xiangguo Wang

Animal Science and Technology College, Beijing University of Agriculture, Beijing 102206, China

Email: xiaolf1989@bua.edu.cn (Longfei Xiao) andxiangguo731@163.com(XiangguoWang)

fax: $+86-10-8709-7311$.

Keywords: Endometritis, T lymphocytes, Exosomes, Treg

\section{Summary}


As a common group-occurring disease, endometritis is caused by endometrial cell injury and chronic inflammation of uteri infected by pathogenic microorganisms, and leads to reproductive failure in dairy cows. Changes in the immune response function of the uteri affect the occurrence and development of endometritis. It was recently discovered that exosomes act as a functional regulator secreted by a variety of cells. However, its regulatory mechanism in the local immune response of the uteri is still unclear. In this study, flow cytometry was adopted to identify that the number of $\mathrm{T}$ lymphocytes in the uteri with endometritis increased while the compositional proportion also changed, namely that of Tc cell increased very significantly and that of Th and Treg cells decreased very significantly. Moreover, the functional marker factor Foxp3 of Treg cells was extremely significantly decreased, and the functional marker factor of Th17 cells was significantly increased. The mRNA expression of immune tolerance regulators PD1, CTLA4 and Galectin-1 in the group of Treg cells which were co-incubated with LPS-stimulated endometrial epithelium-derived exosomes was very significantly lower than in the group of Treg cells which were co-incubated with normal EEC-derived exosomes. Furthermore, the protein expression of PD1, CTLA4, Galectin-1, Foxp3, and IL-17 was consistent with the results in the Treg cells co-incubated with different source exosomes in mice. Therefore, it was demonstrated that endometrial epithelium-derived exosomes act as a vital regulator of changes in the composition and function of $\mathrm{T}$ lymphocyte subsets in the uterus of dairy cows.

Keywords: Endometritis, T lymphocytes, Exosomes, Treg

\section{Introduction}

As a common obstetric disease of dairy cows, endometritis can cause infertility in dairy cows and bring serious economic losses to dairy farming [1]. The occurrence of endometritis is closely related to the immune status of the body, and the role of related immune cells is extremely critical in the process of uterine involution in dairy cows [2].

$\mathrm{T}$ lymphocytes play an essential role in protecting the body against pathogens, mainly by assisting other lymphocytes in playing their corresponding role [3]. T lymphocytes are classified into cytotoxic $\mathrm{T}$ cells (Tc), helper $\mathrm{T}$ cells $(\mathrm{Th})$ and regulatory $\mathrm{T}$ cells (Treg) according to their surface markers and functional classification. Treg cells belong to the unique $\mathrm{T}$ cell subset which is a key regulator of inflammation and plays an important role in maintaining immune tolerance and regulating immune response [4], and are mainly driven by the transcription factor Foxp3 to enhance the lineage development and immunosuppressive function of immune cells [5]. CD4+CD25+Foxp3+Treg cells belong to the CD4+T cell subgroup, which utilizes cell surface molecules such as CTLA-4, IL-2 and GITR to exert immunosuppressive effects and can modulate the activity of antigen-presenting cells (APC) [6-9]. It has been recognized as a sign of CD8+ T cell exhaustion, which plays an important role in the stability and inhibition of Treg cells [10, 11], that PD-1 (programmed cell death-1) and CTLA4 (cytotoxicT-lymphocyte-associated protein 4) jointly promote the inhibitory function of Treg. PD-1. Activated after binding to the corresponding ligand PD-L1, PD-1 can promote the development of tumors and thus inhibit the production of anti-tumor function factors IFN- $\gamma$ and TNF- $\alpha$ by CD8+ T cells [12]. CTLA-4, a competitive antagonist for CD28-CD80/86 binding, can further impede the priming and activation of $\mathrm{T}$ cells, and belongs to the negative regulatory stimulation factor of T cells' functions [13]. CTLA-4 is associated with many autoimmune diseases, and some researches proved that CTLA-4 gene plays a key role in the immune tolerance of maternal-fetal interface and is related to the occurrence of abortion [14]. Galectin-1, as the galectin first discovered, is an anti-inflammatory mediator and also immunosuppressive factor. It can be expressed by Treg cells and has been proved to be associated with inflammatory response, cancer and autoimmune diseases [15-17]. Recent studies have also indicated that Galectin-1 can be used for the treatment of cardiovascular disease and diabetes [18, 19]. Due to the presence of an abnormal number of six cysteine residues, Galectin-1 is prone to oxidative inactivation, which hinders its immunomodulatory activity [20]. However, the mechanism of local T lymphocyte and its immunoregulatory factor in the occurrence and development of cows with endometritis is still unclear.

As a collection of membrane-bound carriers containing complex contents, like proteins, lipids and nucleic acids [21], exosomes can be secreted by a variety of cells, such as nerve cells, epithelial cells, antigen presenting cells (APC), and tumor cells [22]. At present, exosomes are clinically used as biomarkers [23-25], vaccines [26] 
and drug carriers [27] for various diseases, and can also be reasonably modified for therapeutic interventions [26], antigen presentation, and immunomodulation [28].

Therefore, this study analyzed the changes of local $\mathrm{T}$ lymphocyte subsets and the expression of immunoregulatory factors in the uteri of cows with endometritis, as well as the effect of LPS-stimulated endometrial epithelium-derived exosomes on the expression of immunoregulatory factors in Treg cells of healthy uteri and in induced Treg of mice, in order to elucidate the mechanism of endometrium epithelium-derived exosomes in regulating local $\mathrm{T}$ lymphocyte and its immunoregulatory factors in bovine uteri in case of endometritis, and further provide theoretical basis for the research and development of immunotherapeutic agents for cows with endometritis.

\section{Materials and Methods}

\subsection{Acquisition, anatomical and cytological identification of bovine uterus}

This study was performed in accordance with the guidelines of the Animal Ethic Committee of Beijing University of Agriculture (Permit number: SYXK(JING)2015-0004). All the experimental cows were Holstein cows from Beijing Shun Sunshine Farm. Five healthy cows and five cows clinically diagnosed with endometritis, which have similar age, parity and physical condition and not other diseases or oestrus manifestations, were selected from 21 to 35 days after parturition, and their uteri were collected after slaughter. The uterine horns were incised in the fresh uteri in the healthy group and diseased group, respectively, to observe endometrial morphology, color and inflammatory changes. Then mucus secreted from the uterine wall was scraped off and stained with the Diff-Quick staining kit in each group.

\subsection{Identification of local lymphocyte subsets in bovine uterus and sorting of Treg cells}

According to the Bovine Organ Tissue Lymphocyte Extraction Kit (Beijing Solarbio Technoloy Co, Ltd.), lymphocytes of healthy bovine uteri and bovine uteri with endometritis were extracted and placed in RPMI Medium 1640 (containing 10\% exosome-free fetal bovine serum, HEPES2928 mg/l, penicillin 100 U/ml, and streptomycin $100 \mathrm{~g} / \mathrm{ml}$ ) for suspension culture in $5 \% \mathrm{CO} 2$ cell incubator at 37, and identified by flow cytometry the next day (Beijing Keyueda Biotechnology Co., Ltd.), respectively. At the same time, Treg cells were sorted from the lymphocytes isolated from the uteri of healthy cows (Beijing Boyunhui Biotechnology Co., Ltd.).

\subsubsection{Identification of T lymphocyte subsets by flow cytometry}

$100 \mu \mathrm{l}$ cell suspension was taken into flow tubes respectively, mixed with $2 \mathrm{ml}$ Cell Staining Buffer and then centrifuged at $300 \mathrm{~g}$ for 5 minutes to discard the supernatant. Then, $10 \mu \mathrm{l}$ CD4 FITC antibodies and 10 $\mu \mathrm{l}$ CD25 PE antibodies were added to the CD4/CD25 staining tube, $10 \mu \mathrm{l}$ CD8 FITC antibody was to the CD8 staining tube, and 0.5 ug CD3 antibody was to the CD3 tube; the blank control tubes and isotype control ones were set separately. After all tubes were incubated at room temperature in the dark for 20 minutes, $2 \mathrm{ml}$ Cell Staining Buffer was added and mixed well, and the mixture was centrifuged at $300 \mathrm{~g}$ for 5 minutes before the supernatant was discarded. Subsequently, 0.5 ug Goat anti-Mouse IgG-PE was added to the CD3 staining tube and its isotype control tube, mixed well, incubated at room temperature and with the avoidance of light for 30 minutes. Then, $2 \mathrm{ml}$ Cell Staining Buffer was added to mix well, the mixture was centrifuged at $300 \mathrm{~g}$ for 5 minutes, and the supernatant was discarded. Lastly, $0.5 \mathrm{ml}$ Cell Staining Buffer was added to each tube, mixed well, and detected by flow cytometry.2.2.2 Sorting of Treg cells by flow cytometry

The cow's lymphocytes were centrifuged in a $1.5 \mathrm{ml}$ centrifuge tube for $5 \mathrm{~min}$. After the supernatant was absorbed, $10 \mu \mathrm{l}$ cells were aspirated for cell counting. Then $10 \mu \mathrm{l}$ of CD4 and CD25 was added and the mixture was leaved at 4 for $30 \mathrm{~min}$. After centrifugation to retain the pellet, $1 \mathrm{ml}$ PBS was added to re-suspend the cells. Subsequently, the cells were centrifuged at $200 \mathrm{~g}$ for $5 \mathrm{~min}$, the supernatant was discarded, then $500 \mu \mathrm{l}$ M1640 was added to blow off the cells. Finally, the bovine Treg cells were sorted by flow cytometry, pipetted into 24-well plates, supplemented with RPMI Medium 1640 (without exosomes), and cultured in an incubator. 


\subsection{Isolation and identification of exosomes derived from endometrial epithelial cells}

The cows' endometrial epithelial cell line was subcultured and washed with DPBS containing double antibodies. Both groups were added with DMEM/F12 culture solution (added serum without exosomes), and additional $100 \mu \mathrm{g} / \mathrm{ml}$ LPS was added to the experimental group. After incubation for $24 \mathrm{~h}$, the supernatant was stored by centrifugation. Then, exosomes from normal cultured endometrial epithelial cells and those from LPS-treated endometrial epithelial cells were extracted by using of the Exosomes Isolation Kit (Shanghai Bestbio Biotechnology Co., Ltd.), respectively. The two groups of extracted exosomes were identified by electron microscopy and the expression of CD9 marker protein.

\subsection{Incubation of exosomes with cows' Treg cells and mice's T lymphocyte CTLL-2}

The Treg cells of bovine uteri sorted by flow cytometry were detected for the localization and expression of its functional marker FOXP3 by immunofluorescence to ensure the successful sorting of Treg cells. Then the Treg cells were transferred to 6 wells of a 24 -well plate, $100 \mu \mathrm{l}$ of normally cultured bovine endometrium epithelium-derived exosomes were added to 3 wells, and LPS-treated bovine endometrial epithelium-derived exosomes were added to the other 3 wells, before they were cultured for $24 \mathrm{~h}$, respectively. Meanwhile, after the mice's CTLL-2 T lymphocytes were subcultured, the prepared IL-2 M1640 was added to the mice's T lymphocytes and achieved a growth density of $80 \%$ to induce mice's T cells to generate Treg cells. Finally, two previously extracted exosomes were added, respectively, and the mixtures were cultured in an incubator for $24 \mathrm{~h}$.

\subsection{Real-time detection of RT-PCR ( qRT-PCR)}

The mRNA of each treated cell was extracted separately to determine the OD value, and the expressions of CTLA4, PD1 and Galectin1 were determined by qRT-PCR using the primer sequences in Table 1.

\subsection{Western blot analysis}

Total cellular protein was extracted from the treated cell samples of each group, and the protein concentration was calculated. Meanwhile, the separation gel was poured into the gap of the gel slab and then compacted with absolute ethanol, and placed in an incubator for 12 minutes to accelerate solidification. Afterwards, the absolute ethanol was decanted, a comb inserted, and the gel placed in the incubator to solidify. Then it was placed in the electrophoresis tank filled with electrophoresis solution, the comb discarded, the sample added in sequence, and the voltage set to $60 \mathrm{~V}$. After the electrophoresis for $2 \mathrm{~h}$, the proteins of each group were electro-transferred onto PVDF membranes, which then were blocked for $1 \mathrm{~h}$ and incubated with primary antibody (Table 2) at 4 overnight. The next day, the membranes were washed with TBST for 5 times and incubated with the secondary antibody for $1 \mathrm{~h}$ at room temperature. Finally, the immunoreactive bands were visualized with the Gel Image System.

\subsection{Statistical analysis}

Data were analyzed by one-way ANOVA, and the analysis was performed using SPSS software(Version 13.0, SPSS, Chicago, IL, USA) with Tukeys post hoc test. $\mathrm{P}<0.05$ was regarded as statistically significant. All data are represented as the mean SEM of at least three separate experiments.

\section{Results}

\subsection{Anatomical and cytological identification of bovine uteri with endometritis}

The results showed that the inside of the healthy uterus was flesh-colored with a smooth inner wall and a small amount of clear fluid (Figure 1A) and the uterus of the cows with endometritis showed dark red inflammatory tissue inside, with inflamed swelling and ulceration in the inner wall and dark red fluid (Figure 1B). Only exfoliated epithelial cells were presented in healthy uterine luminal fluid (Figure 1C). There were a large number of neutrophils in the uterine luminal fluid with endometritis (Figure 1D).

\subsection{Quantitative analysis of local $\mathrm{T}$ lymphocyte subsets in cows with endometritis}


The results of flow cytometry showed that the numbers of $\mathrm{T}$ cells (CD3+), Th cells (CD4+), Treg cells $(\mathrm{CD} 4+\mathrm{CD} 25+)$ and Tc cells $(\mathrm{CD} 8+)$ in the uteri of the cows with endometritis were very significantly higher than those in the healthy cows (Figure $2 \mathrm{~A}$ and $\mathrm{B}, p<0.01$ ).

3.3 Changes of local $\mathrm{T}$ lymphocyte subsets and main regulatory factors in the uteri of cows with endometritis

Compared with the healthy bovine uteri, the proportion of $\mathrm{T}$ cells (CD3+) did not change, and the proportions of Th cells $(\mathrm{CD} 4+)$ and Treg cells $(\mathrm{CD} 4+\mathrm{CD} 25+)$ both showed a very significant decrease while the proportion of Tc cells (CD8+) in T cells extremely significantly increased (Figure 3A, $p<0.01$ ) in the uteri of cows with endometritis. At the same time, the western blot results also showed that Treg cell (CD4+ CD25+) identification factor FOXP3 was very significantly reduced (Figure 3B and C, $p<0.01$ ), and Th17 cell secreted factor IL-17 expression was significantly increased (Figure 3B and C, $p<0.05$ ).

\subsection{Isolation and identification ofEECexo and LPSexo}

The results showed that both EECexo and LPSexo had a membrane vesicle structure with a diameter between 30 and $150 \mathrm{~nm}$ (Figure 4A), and the exosome marker factor CD9 was expressed in all of them (Figure 4B).

3.5 Effect of EECexo and LPSexo on the expression of $\mathrm{T}$ cell regulatory factors in healthy bovine uteri

The results showed that Treg cells $(\mathrm{CD} 4+\mathrm{CD} 25+)$ were isolated from the uteri of the healthy cows by flow cytometry (Figure 5A), so as to express the functional marker FOXP3 (Figure 5B). Co-incubation of isolated Treg $(\mathrm{CD} 4+\mathrm{CD} 25+)$ and LPSexo very significantly reduced the expression of the immune tolerance regulators PD1, CTLA4, and Galectin1 (Figure 5C, $p<0.01$ ).

\subsection{Effect of EECexo and LPSexo on the expression of $T$ cell regulatory factors in mice}

CTLL2 cells cultured in vitro were supplemented with IL2 for growth promotion, then incubated with EECexo and LPSexo, respectively. Co-incubation of CTLL2 and EECexo very significantly increased the expressions of immune tolerance regulators PD1 and Galectin1 (Figures $6 \mathrm{~A}$ and $6 \mathrm{~B}, p<0.01$ ), significantly increased the expressions of FOXP3 and CTLA4 (Figure 6A and 6B, $p<0.05$ ), and significantly decreased the expression of the immune proinflammatory factor IL17 (Figures 6A and 6B, $p<0,05$ ). Co-incubation of CTLL2 and LPSexo caused a significant decrease in PD1 and Galectin1 compared to the normal culture of CTLL2 (Figures 6A and 6B, $p<0,05$ ), however, compared with the CTLL2-EECexo group, the expressions of PD1, CTLA4 and Galectin1 were very significantly reduced (Figures $6 \mathrm{~A}$ and $6 \mathrm{~B}, p<0,01$; Figure S2), FOXP3 expression was significantly reduced (Figures $6 \mathrm{~A}$ and $6 \mathrm{~B}, p<0,05$ ), the expression of the immune proinflammatory factor IL17 was significantly increased (Figures $6 \mathrm{~A}$ and $6 \mathrm{~B}, p<0,05$ ).

\section{Discussion}

The main leukocyte subtypes in the uteri of normal non-pregnant cows are $\mathrm{T}$ lymphocytes, macrophages and neutrophils (polymorphonuclear, PMN). In this study, a large number of exfoliated epithelial cells were predominant in the uterine luminal fluid of normal non-pregnant cows, and a large number of PMN infiltrated in the uterine luminal fluid of cows with endometritis. T lymphocytes mainly include CD4+ (helper), CD8+ (cytotoxin) and CD2+ subsets. The migration and distribution of these cells play an important role in the local immunity of the uteri of dairy cows. The study on the changes in the numbers of CD4+ and CD8+ T cell subsets in the blood of cows will help to further understand the cellular immune defense mechanism of the uteri. Previous studies have found that in the blood of cows with clinical endometritis, the percentage of CD4+T cells showed an upward trend and that of CD8+ T cells showed a downward trend in the early postpartum period, while that of CD4 $+\mathrm{T}$ cells showed a rapid decrease and that of CD8 $+\mathrm{T}$ cells showed a rapid increase at the late postpartum period [29]. The uteri of cows with endometritis were collected from the 21st to 35th postpartum days in this research. During this period, the percentage of CD4+ T cells in the uteri showed a rapid downward trend, and that of CD8 $+\mathrm{T}$ cells showed a rapid upward trend. Our results also confirmed that the occurrence of clinical endometritis is caused by the further deterioration of uterine 
inflammation and the massive activation of cytotoxic $\mathrm{T}$ lymphocytes, because the proliferation of helper $\mathrm{T}$ lymphocytes is inhibited and then the immunity of dairy cows is reduced in this case. Meanwhile, the expression of Foxp3, which plays a key role in regulating immune homeostasis, was significantly decreased, and that of IL-17, a soluble factor induced by T cells and promoting the development of inflammation, was significantly increased.

Treg has long been recognized as an effective inhibitor of the immune system, and the normal number and function of Treg is an important prerequisite for maintaining homeostasis in the body, so their insufficient number may be a sign of immune dysregulation[30]. Treg cells can inhibit immune response by secreting a variety of cytokines. For example, constitutively expressed CTLA-4 on Treg cells preferentially binds to and downregulates CD80/CD86 costimulatory molecules on antigen-presenting cells, causing Tconv cells to lose costimulatory signals [31]. PD-1 modulates Treg suppressive properties as well as Treg-Teff cell interaction [32]. Galectin-1 can also promote the expansion of Treg cells and inactivate antigen-presenting cells [18]. Th17 can participate in the occurrence and development of various inflammations, autoimmune diseases and tumors [33]. It has also been confirmed that Th17 and Treg can transform each other under certain conditions and jointly participate in the mechanism of disease development [34]. Lee [35] found that Treg cells can also secrete the cytokine IL-17, indicating that Treg cells not only inhibit the body's inflammatory state, but may also be involved in the Th17-dominated proinflammatory response. In this study, it was found that the Th17/Treg in the uteri of cows with endometritis showed an imbalance compared with healthy cows. The imbalance of Th17/Treg was reflected in the increased in IL-17 secreted by proinflammatory Th17 cells, while the content of Foxp3, CTLA4, PD-1, and galectin-1 secreted by Treg cells was decreased, which is consistent with our results. In addition, Tc cells, belonging to CD8+ T cells, play an crucial role in anti-tumor [36] and anti-virus behavior[37]. The cytotoxic effect of Tc cells can specifically kill those corresponding target cells. Therefore, the increased proportion of Tc cells may be a possible cause of embryo killing, leading to abortion of dairy cows suffering from endometritis. Therefore, controlling the proportion of Tc cells in the uteri and regulating the Th17/Treg balance may provide an effective target site of immune agents for cows with endometritis.

The accumulative evidences suggest that exosomes can act as new mediators of intercellular signal transmission between adjacent cells as well as between distant tissues [38], and work either independently or synergistically with soluble growth factors and hormones [39]. Exosomes can transmit mRNAs, miRNAs, and etc. to other cells so that they can play further roles in recipient cells [40, 41]. Endometrial epithelial cells, as the first barrier to contact with pathogens, can communicate with immune cells by releasing cytokines such as TNF- $\alpha$, IL-1, IL-6, and IL-8, so that they exert an immune response function [42, 43]. In order to confirm the role of endometrial epithelium-derived exosomes in regulating the immune function in the uteri of cows with endometritis, we successfully isolated and identified endometrial epithelium-derived exosomes from the supernatant of the cultured endometrial epithelial cells and co-incubated them with the uterine-derived Treg cells from the healthy cows, respectively. The results showed that LPSexo decreased the expressions of the immune homeostasis regulators CTLA4, PD-1, and Galectin-1, which is consistent with the local uterine changes in cows with endometritis. Furthermore, we incubated exosomes from different sources with the induced Treg cells from model animal mice. The data revealed that EECexo was inclined to promote the expressions of the immune homeostasis regulators Foxp3, CTLA4, PD-1, and galectin-1, inhibit the expression of the Inflammatory cytokines IL17, maintain an immune tolerance homeostasis in the uteri, and have an important regulatory role for embryonic survival. Conversely, LPSexo was inclined to inhibit the expressions of immune homeostasis regulators Foxp3, CTLA4, PD-1 and Galectin-1, and promote the expression of the inflammatory factor IL-17. Therefore, we conjecture that normal endometrial epithelial cell-derived exosomes have a natural function in regulating local uterine immunity, and this function is mainly reflected in immune tolerance, that is, normal endometrial epithelium-derived exosomes may contain the related factors that can act on immune cells which can fuse with Treg cells to increase the secretion of Treg-associated immunosuppressive factors, and thus inhibit the local uterine inflammatory response and ensure the survival of embryos in the uteri. However, the exosomes produced by epithelial cells in case of endometritis can act on Treg cells to change their original immunosuppressive state, from immune inhibition 
to immune activation. Moreover, uteri, as a special organ of animal body, are not only affected by microbial infection under the condition of endometrium inflammation, but also regulated by the hormone in different estrus cycles and pregnant stages. Further research is needed on the regulatory role of exosomes and their inclusions toward uterine function.

To summarize, the imbalance of Th17/Treg and increased proportion of inflammatory cells in the uteri are important reasons for the occurrence and development of endometritis and affecting the conception of dairy cows (Figure 7). In addition, the influencing mechanism of endometrial epithelium-derived exosomes on uterine immunoregulation is worthy of further exploration, so as to provide new ideas and methods for the clinical diagnosis of cows with endometritis and the research and development of immune agents.

\section{Acknowledgements}

This research was supported by the National Natural Science Foundation of China (NO. 31802263), National Key R\&D Program of China (Project No. 2017YFD0502200), Beijing dairy cattle industry innovation team project (NO. BAIC05-2017), Beijing municipal education commission science and technology plan general projects (No. KM201810020007) and Outstanding young talent project of beijing municipal party committee organization department(No. 065).

\section{Disclosure}

The authors declare that they have no competing interests

\section{Authors' contributions}

Xiangguo Wang and Hong An designed the experiments and interpreted the data and wrote the article. Hong An performed the experiments with assistance and advice from Bofan Fu, Xinxin Yao and Yong Guo. Hemin $\mathrm{Ni}$ conducted data analysis. Longfei Xiao revised the manuscript. All authors have read the manuscript and approved to submit it to your journal.

\section{Availability of data and materials}

All data generated or analyzed during this study are available from the corresponding author on reasonable request.

\section{Consent for publication}

Not applicable.

\section{Ethics approval and consent to participate}

All experimental and surgical procedures involving animals were approved by the Beijing Laboratory Animal Management Committee.

\section{Reference}

1. Mounir A, Rachid K, Christian H, England GCWJTJoV, Sciences A. Risk factors of clinical and subclinical endometritis in cattle: a review. 2017; $41: 1-11$.

2. Brodzki P, Kostro K, Brodzki A, Lisiecka U. Determination of selected parameters for non-specific and specific immunity in cows with subclinical endometritis. Animal reproduction science 2014;148:109-14.

3. Kuwabara T, Matsui Y, Ishikawa F, Kondo M. Regulation of T-Cell Signaling by Post-Translational Modifications in Autoimmune Disease. International journal of molecular sciences 2018;19 .

4. Göschl L, Scheinecker C, Bonelli M. Treg cells in autoimmunity: from identification to Treg-based therapies. Seminars in immunopathology 2019; $41: 301-14$.

5. Deng G, Song X, Fujimoto S, Piccirillo CA, Nagai Y, Greene MI. Foxp3 Post-translational Modifications and Treg Suppressive Activity.Frontiers in immunology 2019; $10: 2486$. 
6. Mao QF, Shang-Guan ZF, Chen HL, Huang K. Immunoregulatory role of IL-2/STAT5/CD4+CD25+Foxp3 Treg pathway in the pathogenesis of chronic osteomyelitis. Annals of translational medicine 2019;7 :384.

7. Mahne AE, Mauze S, Joyce-Shaikh B, Xia J, Bowman EP, Beebe AM, Cua DJ, Jain R. Dual Roles for Regulatory T-cell Depletion and Costimulatory Signaling in Agonistic GITR Targeting for Tumor Immunotherapy.Cancer research 2017; 77 :1108-18.

8. Zhao L, Zhou X, Zhou X, Wang H, Gu L, Ke Y, Zhang M, Ji X, Yang X. Low expressions of PD-L1 and CTLA-4 by induced CD4(+)CD25(+) Foxp3(+) Tregs in patients with SLE and their correlation with the disease activity. Cytokine 2020; 133 :155119.

9. Lu L, Barbi J, Pan F. The regulation of immune tolerance by FOXP3. Nature reviews Immunology 2017; $17: 703-17$.

10. Bengsch B, Johnson AL, Kurachi M, Odorizzi PM, Pauken KE, Attanasio J, Stelekati E, McLane LM, Paley MA, Delgoffe GM, Wherry EJ. Bioenergetic Insufficiencies Due to Metabolic Alterations Regulated by the Inhibitory Receptor PD-1 Are an Early Driver of CD8(+) T Cell Exhaustion. Immunity 2016; 45 :358-73.

11. Ahn E, Araki K, Hashimoto M, Li W, Riley JL, Cheung J, Sharpe AH, Freeman GJ, Irving BA, Ahmed R. Role of PD-1 during effector CD8 T cell differentiation. Proceedings of the National Academy of Sciences of the United States of America 2018; $115: 4749-54$.

12. Gao CE, Zhang M, Song Q, Dong J. PD-1 inhibitors dependent CD8(+) T cells inhibit mouse colon cancer cell metastasis. OncoTargets and therapy 2019; $12: 6961-71$.

13. Rowshanravan B, Halliday N, Sansom DM. CTLA-4: a moving target in immunotherapy. Blood 2018; $131: 58-67$.

14. Li L, Liu J, Qin S, Li R. Correlation between CTLA4 genetic polymorphisms, its serum protein level and the susceptibility to recurrent spontaneous abortion: A case-control study. Medicine 2018; 97 :e12754.

15. Toscano MA, Martínez Allo VC, Cutine AM, Rabinovich GA, Mariño KV. Untangling Galectin-Driven Regulatory Circuits in Autoimmune Inflammation. Trends in molecular medicine 2018;24 :348-63.

16. Nambiar DK, Aguilera T, Cao H, Kwok S, Kong C, Bloomstein J, Wang Z, Rangan VS, Jiang D, von Eyben R, Liang R, Agarwal S, Colevas AD, Korman A, Allen CT, Uppaluri R, Koong AC, Giaccia A, Le QT. Galectin-1-driven T cell exclusion in the tumor endothelium promotes immunotherapy resistance. The Journal of clinical investigation 2019;129:5553-67.

17. Brinchmann MF, Patel DM, Iversen MH. The Role of Galectins as Modulators of Metabolism and Inflammation. Mediators of inflammation 2018; $2018: 9186940$.

18. Seropian IM, González GE, Maller SM, Berrocal DH, Abbate A, Rabinovich GA. Galectin-1 as an Emerging Mediator of Cardiovascular Inflammation: Mechanisms and Therapeutic Opportunities. Mediators of inflammation 2018; $2018: 8696543$.

19. Al-Obaidi N, Mohan S, Liang S, Zhao Z, Nayak BK, Li B, Sriramarao P, Habib SL. Galectin-1 is a new fibrosis protein in type 1 and type 2 diabetes. FASEB journal : official publication of the Federation of American Societies for Experimental Biology 2019; 33 :373-87.

20. Guardia CM, Caramelo JJ, Trujillo M, Méndez-Huergo SP, Radi R, Estrin DA, Rabinovich GA. Structural basis of redox-dependent modulation of galectin-1 dynamics and function. Glycobiology 2014;24 :428-41.

21. Barile L, Vassalli G. Exosomes: Therapy delivery tools and biomarkers of diseases. Pharmacology \& therapeutics 2017;174:63-78.

22. Cordonnier M, Chanteloup G, Isambert N, Seigneuric R, Fumoleau P, Garrido C, Gobbo J. Exosomes in cancer theranostic: Diamonds in the rough. Cell adhesion \& migration 2017; 11 :151-63. 
23. Dixon CL, Sheller-Miller S, Saade GR, Fortunato SJ, Lai A, Palma C, Guanzon D, Salomon C, Menon R. Amniotic Fluid Exosome Proteomic Profile Exhibits Unique Pathways of Term and Preterm Labor. Endocrinology 2018; $159: 2229-40$.

24. Ludwig N, Razzo BM, Yerneni SS, Whiteside TL. Optimization of cell culture conditions for exosome isolation using mini-size exclusion chromatography (mini-SEC). Experimental cell research 2019;378 :149-57.

25. Sharma A, Johnson A. Exosome DNA: Critical regulator of tumor immunity and a diagnostic biomarker. Journal of cellular physiology 2020; 235 :1921-32.

26. He C, Zheng S, Luo Y, Wang B. Exosome Theranostics: Biology and Translational Medicine. Theranostics $2018 ; 8: 237-55$.

27. Alvarez-Erviti L, Seow Y, Yin H, Betts C, Lakhal S, Wood MJ. Delivery of siRNA to the mouse brain by systemic injection of targeted exosomes. Nature biotechnology 2011; 29 :341-5.

28. Zhu T, Wang Y, Jin H, Li L. The role of exosome in autoimmune connective tissue disease. Annals of medicine $2019 ; \mathbf{5 1}: 101-8$.

29. Brodzki P, Kostro K, Brodzki A, Lisiecka U, Kurek L, Marczuk J. Phenotyping of leukocytes and granulocyte and monocyte phagocytic activity in the peripheral blood and uterus of cows with endometritis. Theriogenology 2014; 82 :403-10.

30. Li H, Yang D, Tang Z. Bcl2 like protein-12 suppresses Foxp3(+) regulatory T cells in patients with rheumatoid arthritis.American journal of translational research 2019; $11: 3048-55$.

31. Tanaka A, Sakaguchi S. Regulatory T cells in cancer immunotherapy. Cell research 2017; 27 :109-18.

32. Gianchecchi E, Fierabracci A. Inhibitory Receptors and Pathways of Lymphocytes: The Role of PD-1 in Treg Development and Their Involvement in Autoimmunity Onset and Cancer Progression. Frontiers in immunology 2018; 9 :2374.

33. Asadzadeh Z, Mohammadi H, Safarzadeh E, Hemmatzadeh M, Mahdian-Shakib A, Jadidi-Niaragh F, Azizi G, Baradaran B. The paradox of Th17 cell functions in tumor immunity. Cellular immunology 2017;322 $: 15-25$.

34. Yang C, Cui F, Chen LM, Gong XY, Qin B. Correlation between Th17 and nTreg cell frequencies and the stages of progression in chronic hepatitis B. Molecular medicine reports 2016; 13 :853-9.

35. Lee GR. The Balance of Th17 versus Treg Cells in Autoimmunity. International journal of molecular sciences 2018;19 .

36. Maimela NR, Liu S, Zhang Y. Fates of CD8+ T cells in Tumor Microenvironment. Computational and structural biotechnology journal 2019; $17: 1-13$.

37. Hickman HD. Imaging CD8(+) T cells during diverse viral infections. Intravital 2015; 4 :e1055425.

38. Wortzel I, Dror S, Kenific CM, Lyden D. Exosome-Mediated Metastasis: Communication from a Distance. Developmental cell 2019;49:347-60.

39. Ng YH, Rome S, Jalabert A, Forterre A, Singh H, Hincks CL, Salamonsen LA. Endometrial exosomes/microvesicles in the uterine microenvironment: a new paradigm for embryo-endometrial cross talk at implantation. PloS one 2013; 8 :e58502.

40. Hergenreider E, Heydt S, Tréguer K, Boettger T, Horrevoets AJ, Zeiher AM, Scheffer MP, Frangakis AS, Yin X, Mayr M, Braun T, Urbich C, Boon RA, Dimmeler S. Atheroprotective communication between endothelial cells and smooth muscle cells through miRNAs. Nature cell biology 2012; 14 :249-56.

41. Zhang J, Li S, Li L, Li M, Guo C, Yao J, Mi S. Exosome and exosomal microRNA: trafficking, sorting, and function. Genomics, proteomics \& bioinformatics 2015; 13 :17-24. 
42. Yin P, Zhang Z, Li J, Shi Y, Jin N, Zou W, Gao Q, Wang W, Liu F. Ferulic acid inhibits bovine endometrial epithelial cells against LPS-induced inflammation via suppressing NK- $\chi \mathrm{B}$ and MAPK pathway.Research in veterinary science $2019 ; 126: 164-9$.

43. Lyu A, Chen JJ, Wang HC, Yu XH, Zhang ZC, Gong P, Jiang LS, Liu FH. Punicalagin protects bovine endometrial epithelial cells against lipopolysaccharide-induced inflammatory injury. Journal of Zhejiang University Science B 2017; 18 :481-91.

\section{Figures}
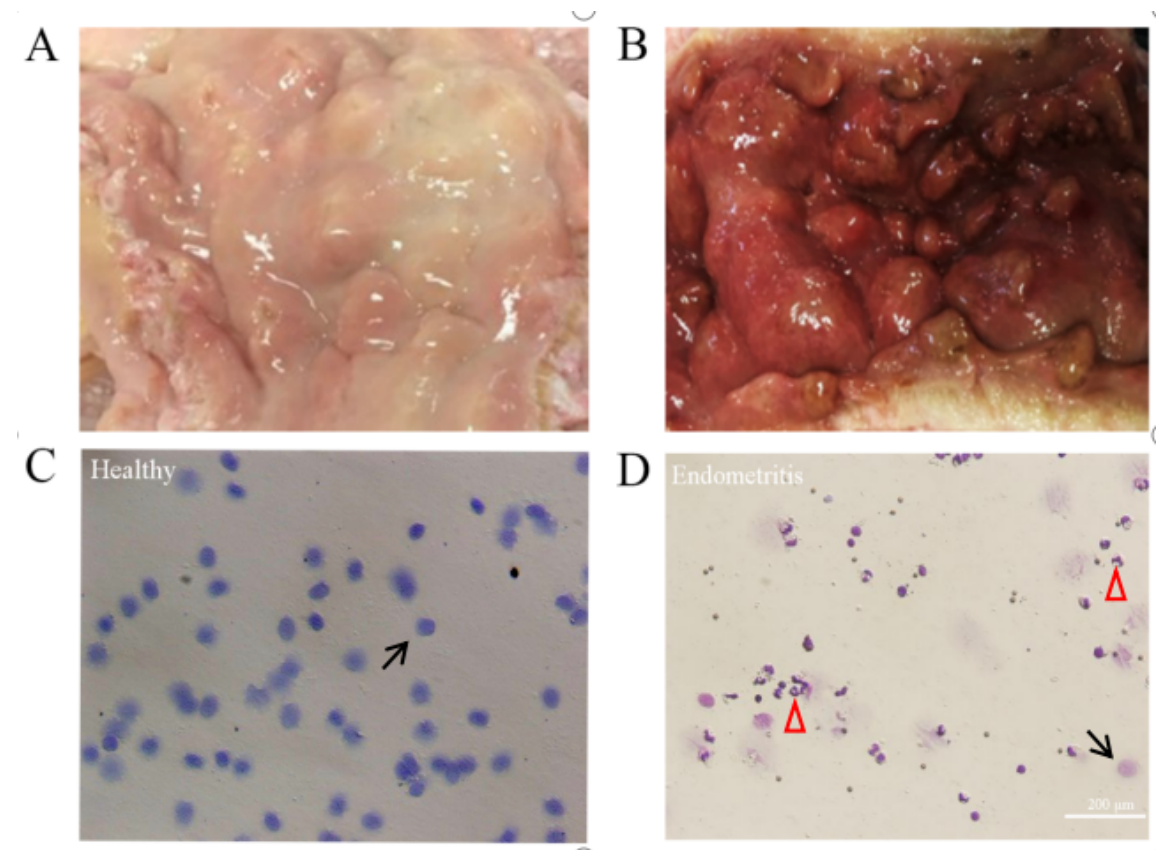

Fig 1. Anatomical and cytological identification of cows' uterus. (A)Endometrial cavity of healthy cows. (B)Endometrial cavity of cows with endometritis. (C) Uterine lavage fluid for cell smear in healthy cows (D) Uterine lavage fluid for cell smear in cows with endometritis. The triangle indicates the shed epithelial cells of the uterus and the arrow points for the Neutrophil. 
A


Endometritis
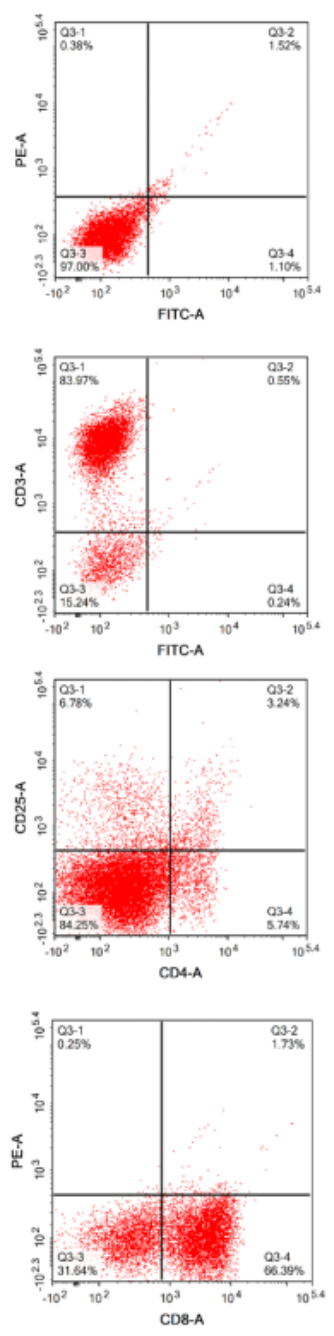

B
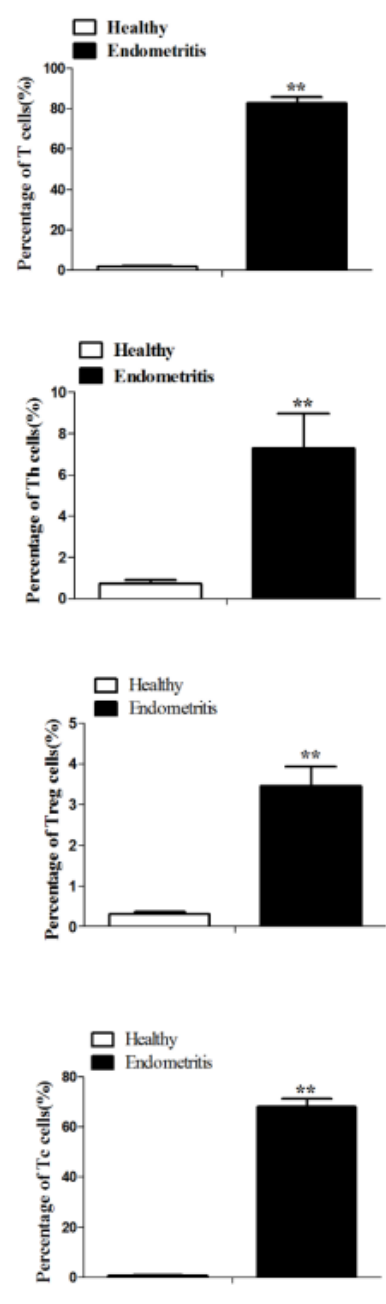

Fig 2. Comparison of the numbers of $T$ lymphocyte subsets between healthy cows and those with endometritis. (A, B) Uteri were collected from the healthy cows and cows with endometritis, lymphocytes were isolated using lymphocyte separating medium, and the changes in the number of $\mathrm{T}$ cells $(\mathrm{CD} 3+)$, Th cells $(\mathrm{CD} 4+)$, Treg cells $(\mathrm{CD} 4+\mathrm{CD} 25+)$ and Tc cells $(\mathrm{CD} 8+)$ were counted by flow cytometry. "** $p$ " $<0.01$ 


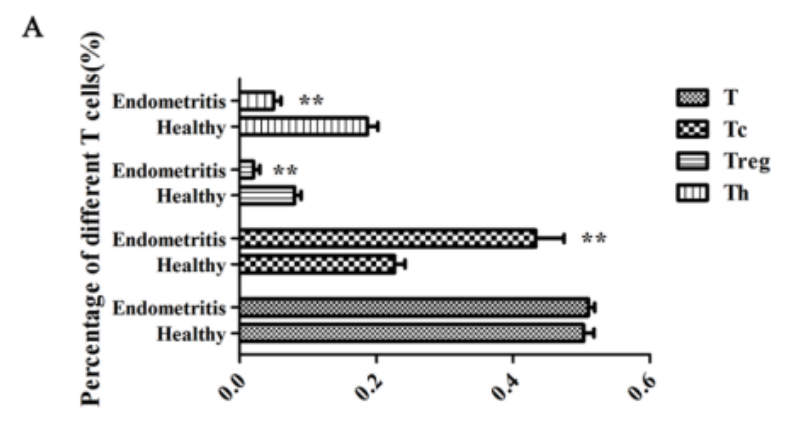

B

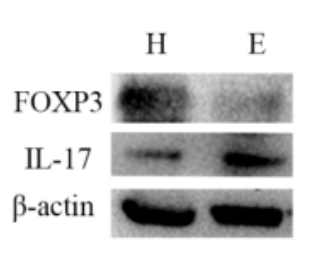

C

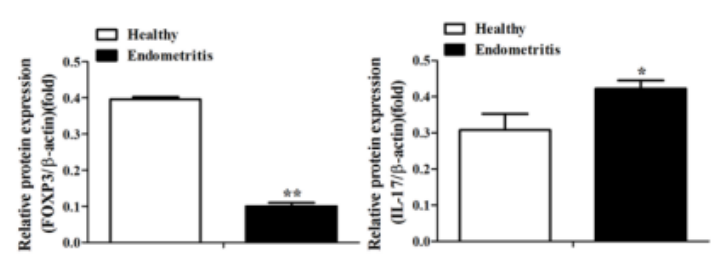

Fig 3. Analysis of the differentiation of $T$ lymphocytes in the uteri of cows with endometritis. (A)The ratio of the number of each $\mathrm{T}$ lymphocyte subset to that of total $\mathrm{T}$ lymphocytes measured by flow cytometry. $(\mathrm{B}, \mathrm{C})$ Western blot detected the expression of Th17 cell-secreted factor IL-17 and Treg cell (CD4+CD25+) marker factor FOXP3. "** $p<0.05$, “**” $p<0.01$.

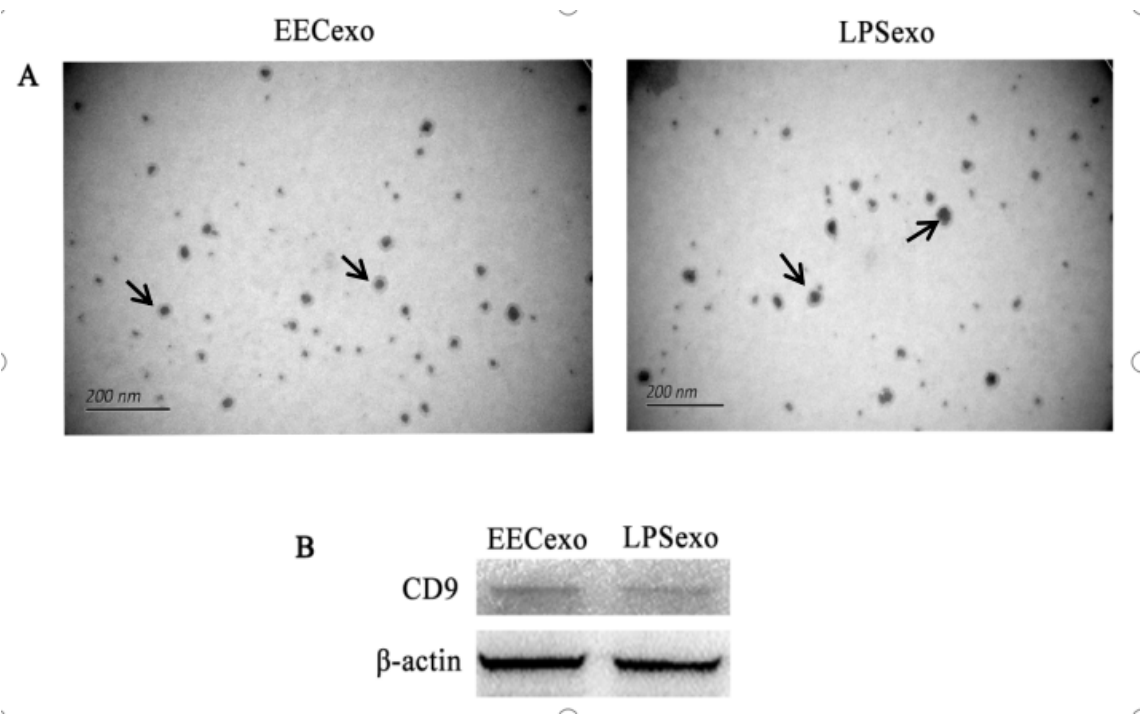

Fig 4. Isolation and identification of exosomes derived from endometrial epithelial cells. Exosomes (named EECexo) were isolated from the normal cultured endometrial epithelial cells (with the serum without exosomes added) by using of Bestbio Exosome Extraction Kit (for cell supernatant). Exosomes (named LPSexo) were isolated from the culture medium of bovine endometrial epithelial cells with $100 \mu \mathrm{g} / \mathrm{ml}$ LPS added after $24 \mathrm{~h}$. (A) Morphological analysis by transmission electron microscopy. (B)Western blot analysis of exosomal marker CD9 protein. Exosomes are indicated with black arrows. 
A

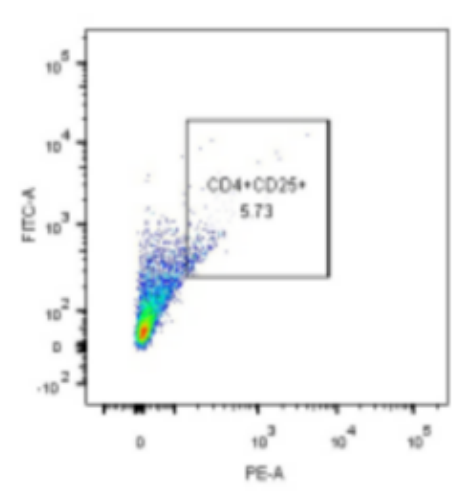

B

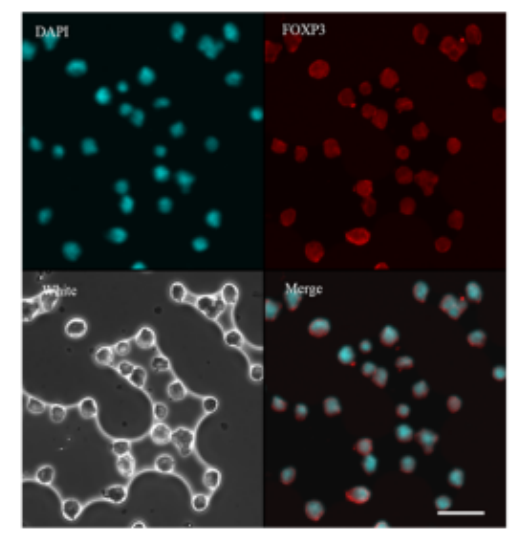

C
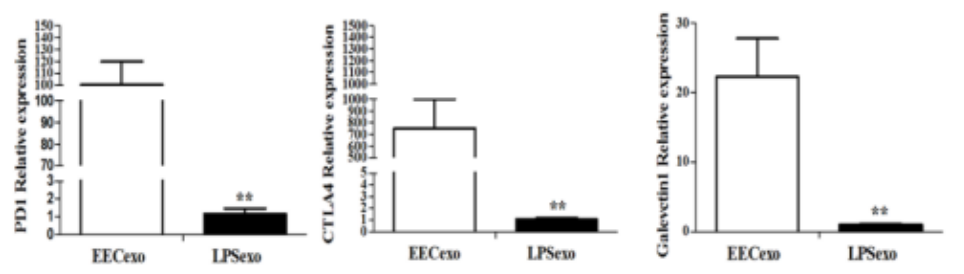

Fig 5. Effect of exosomes on the function of Treg cells $(\mathrm{CD} 4+\mathrm{CD} 25+)$ derived from endometrium. (A) Treg cells (CD4+ CD25+) derived from the uteri of healthy dairy cows as isolated by flow cytometry. (B) The localization and expression of FOXP3, a functional marker of isolated Treg cells (CD4+ CD25+), as detected by immunofluorescence. (C) The isolated Treg cells (CD4+CD25+) were incubated with EECexo and LPSexo for $24 \mathrm{~h}$ respectively, and the expression changes of immune tolerance regulators PD1, CTLA4 and Galectin1 as detected with qRT-PCR. "**" $P<0.01$.

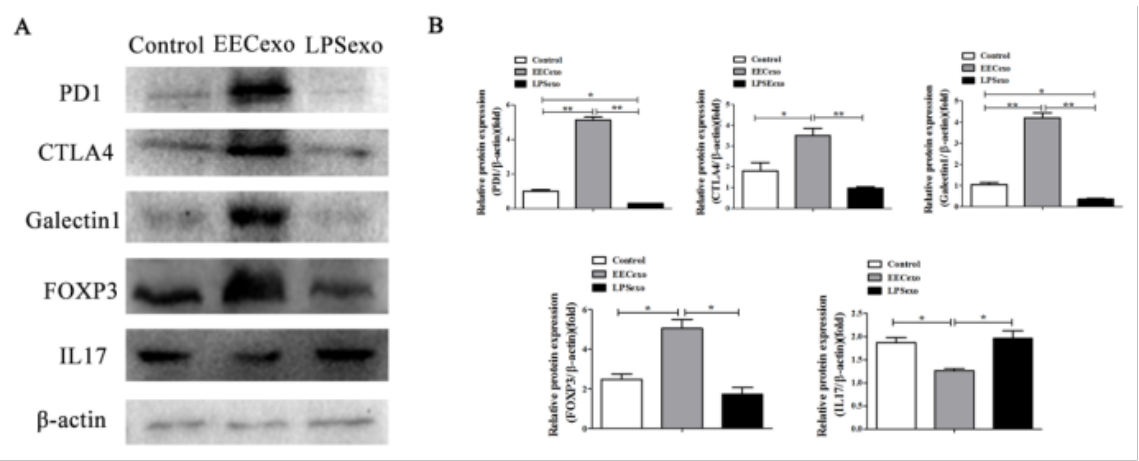

Fig 6 . Effect of the exosomes on the differentiation of activated T Lymphocytes (CTLL2) of mice. CTLL2 cells cultured in vitro were supplemented with IL2 to promote their growth for $24 \mathrm{~h}$ and then incubated with EECexo and LPSexo, respectively. (A) The expressions of the immune marker factors PD1, CTLA4, Galectin1, FOXP3, and IL-17 as detected by western blotting. "**" $p<0.05$, "**” $<p 0.01$. 


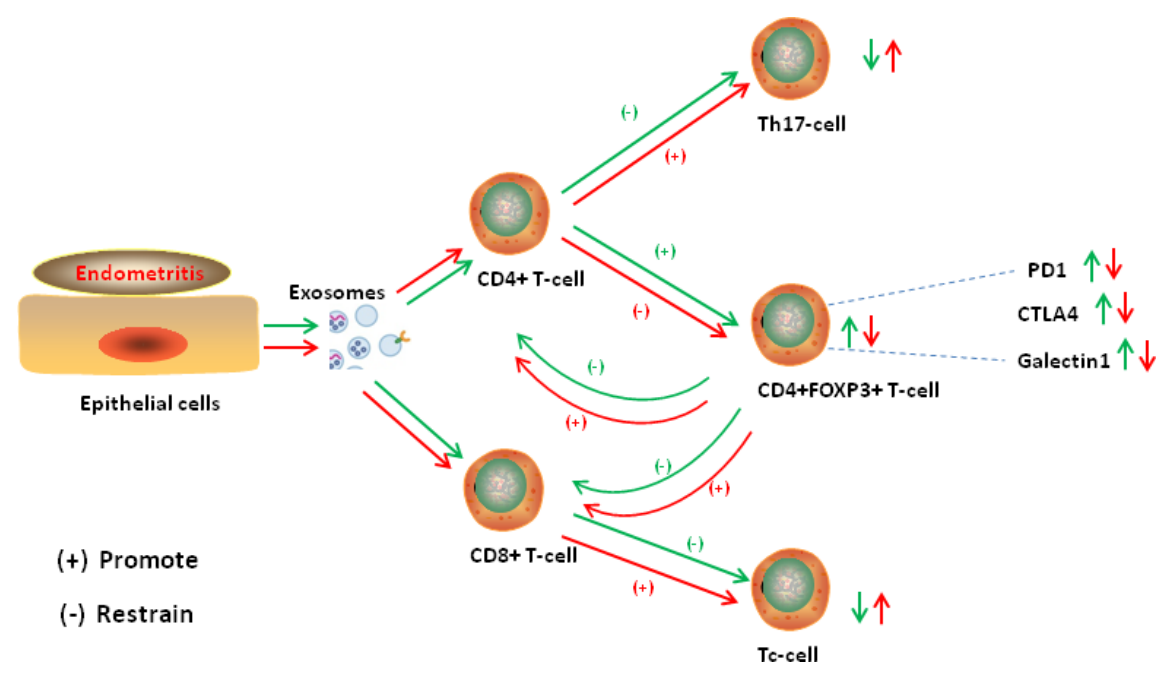

Fig 7 Schematic diagrams showing that endometrial epithelial cell-derived exosomes regulate the imbalance of Th17/Treg and the increase proportion of inflammatory cells in the uteri under healthy or endometritis inflammatory conditions.
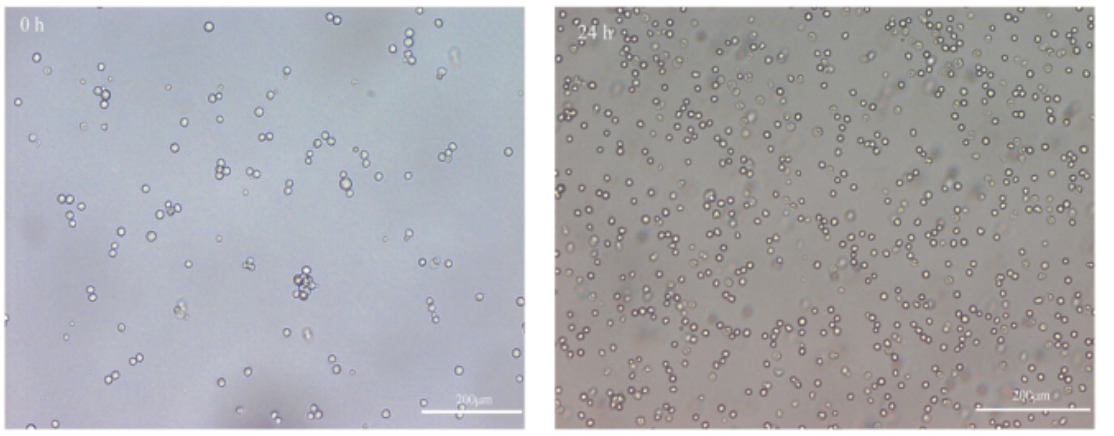

Fig S1. Mice's T lymphocyte (CTLL2) culture. 


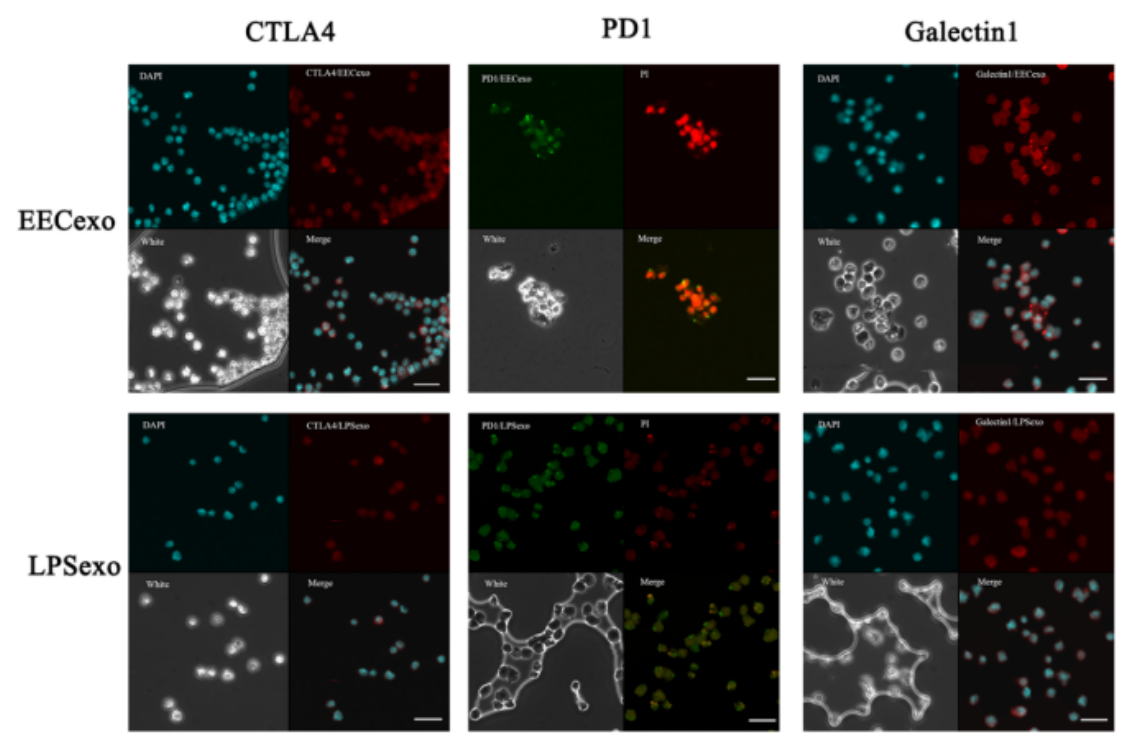

Fig S2. The effect of exosomes on the localization of immune tolerance factors in mice's T lymphocytes (CTLL2). After CTLL2 is incubated with EECexo and LPSexo respectively, the expression and localization of PD1, CTLA4 and Galectin1 as detected by immunofluorescence.

\section{Tables}

Table 1 CTLA4、PD1 、 Galectin1, GAPDH gene primers

\begin{tabular}{ll}
\hline Gene name & sequence \\
\hline CTLA4-FO & TCTAAAGGGATGAATGTGACCCAG \\
CTLA4-RE & ACCTCGTCAGCTTTGCCTGAA \\
PD1-FO & CTGTCACAGTGGACTACGGG \\
PD1-RE & GAAGACGATGGTGGCGTACT \\
Galectin1-FO & AAGTGTCGTGGAGGTATGCA \\
Galectin1-RE & ACAGGTAGTTGATGGCCTCC \\
Bos GAPDH 1P1S & GGCGTGAACCACGAGAAGTA \\
Bos GAPDH 1P2A & GGCGTGGACATGGTCATAA \\
\hline
\end{tabular}

Table 2 Antibody used in this study

Target(diluted)

CD8 Monoclonal Antibody (38.65)

CD4 Monoclonal Antibody (CC8)

CD25 Monoclonal Antibody (IL-A111)

Anti-BOVINE CD3

Goat Anti-Mouse IgG

Anti-CD9 antibody

Rabbit Anti-beta-Actin (Loading Control) antibody(1:10000)

Rabbit Anti-IL-17 Polyclonal Antibody(1:1000)

Rabbit Anti-IL17E antibody(1:1000)

Rabbit Anti-FoxP3 antibody(1:1000)

Anti-CTLA4 antibody [CAL49](1:1000)
Table 2 Antibody used in this study

Catalogue number
MA1-80900
MA1-80902
MA5-28330
WS0561B-100
1030-09S
ab92726
bs-0061R

Rabbit Anti-IL-17 Polyclonal Antibody(1:1000)

bs-10943R

bs-10211R

ab237712
Table 2 A

Catalogue

MA1-809

MA1-809

MA5-283

WS0561B

1030-09S

ab92726

bs-0061R

bs-1183R

bs-10943I

bs-10211I

ab237712 
Table 2 Antibody used in this study

Anti-PD1 antibody [EPR20665](1:1000)

Anti-Galectin 1 antibody [6C8.4-1](1:1000)
Table 2 Antibody used in this study

ab214421

ab205889
Table 2 A

ab214421

ab205889

\section{Hosted file}

Tables.docx available at https://authorea.com/users/343119/articles/469783-the-effectsof-endometrial-epithelium-derived-exosomes-on-the-recruitment-and-activation-of-tlymphocytes-in-the-uteri-of-dairy-cows

A

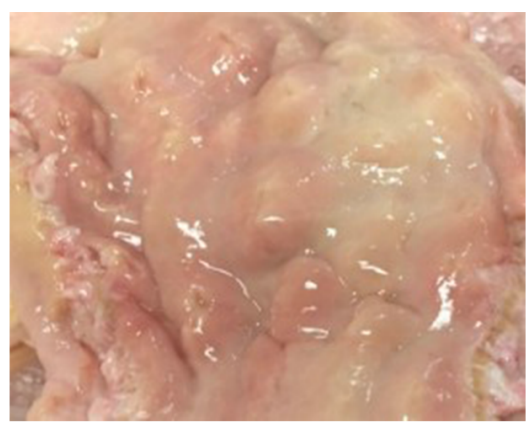

C

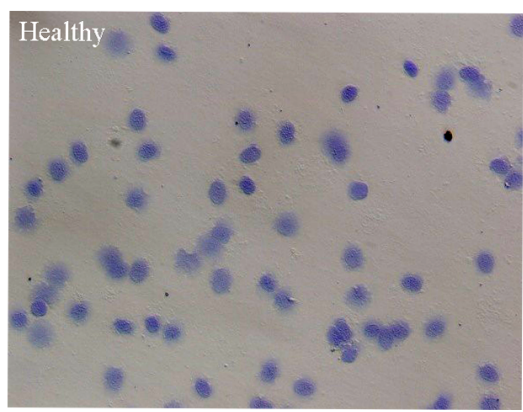

B

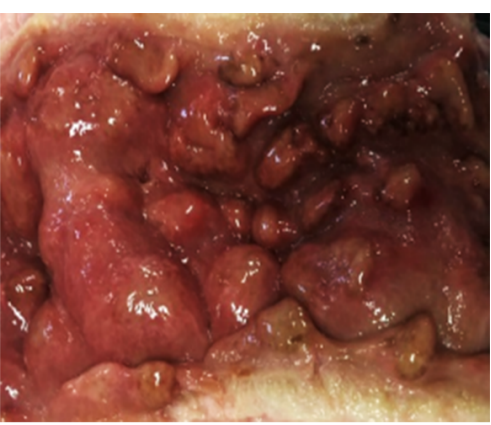

$\mathrm{D}$

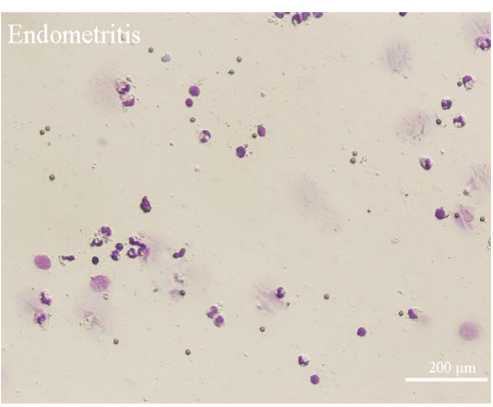


A

\section{Healthy}
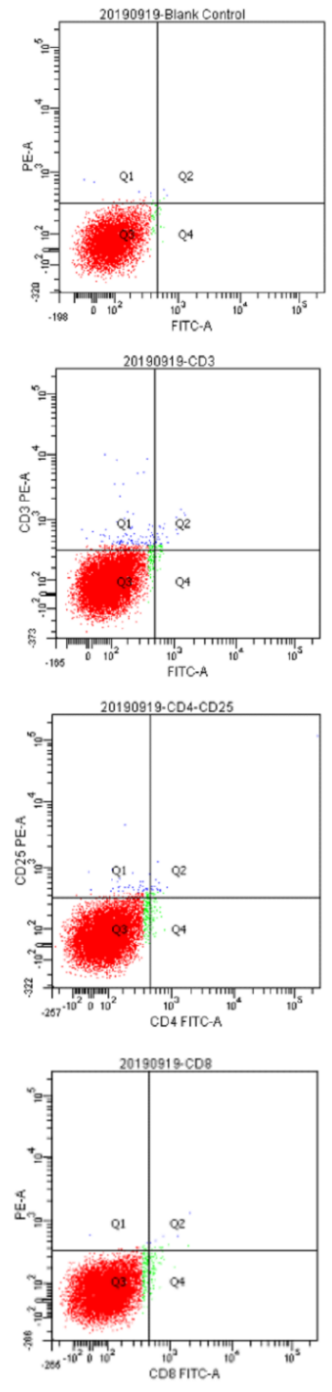

Endometritis
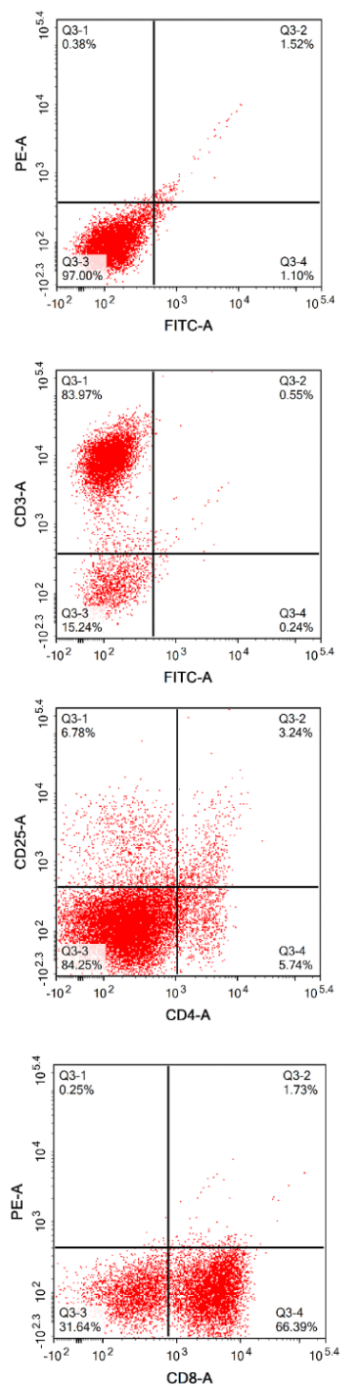

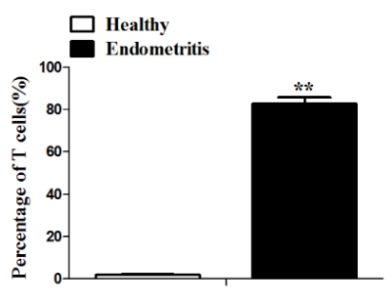

B

A

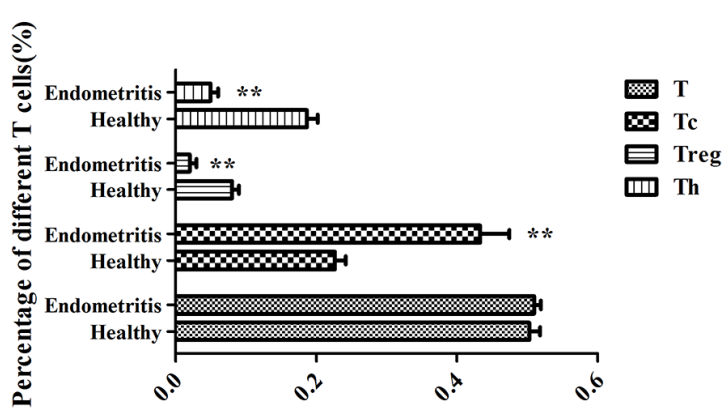

B

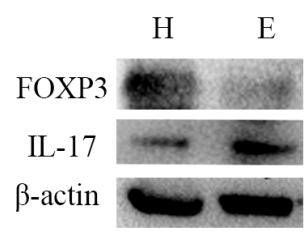

C

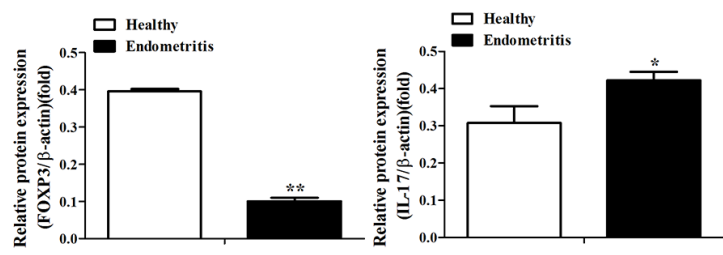

EECexo
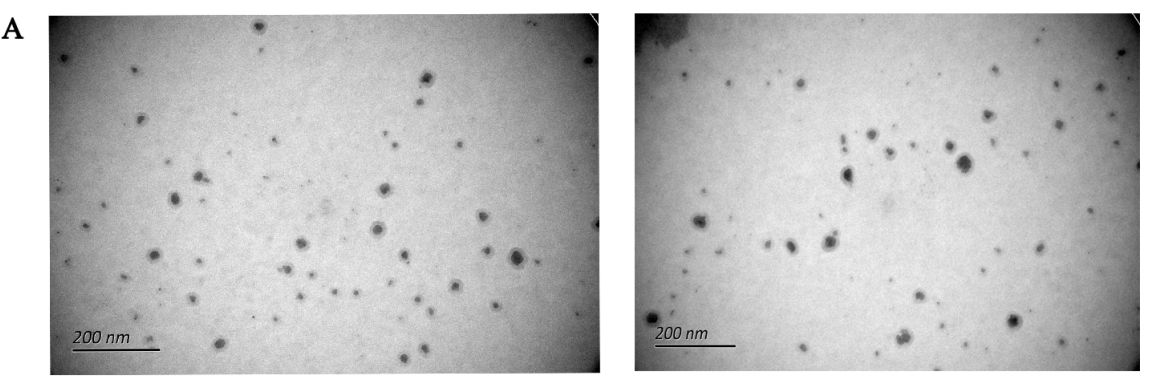

B
EECexo LPSexo

CD9

$\beta$-actin 
A

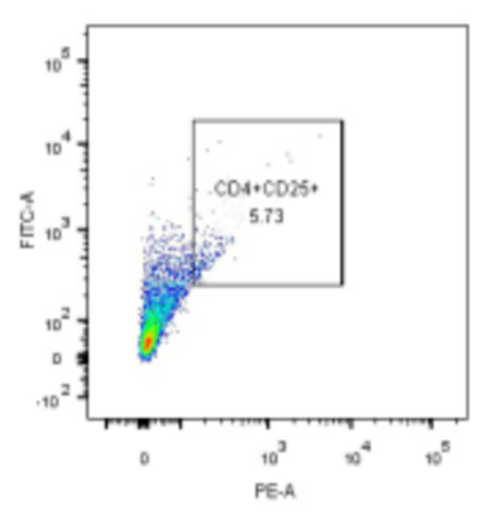

B

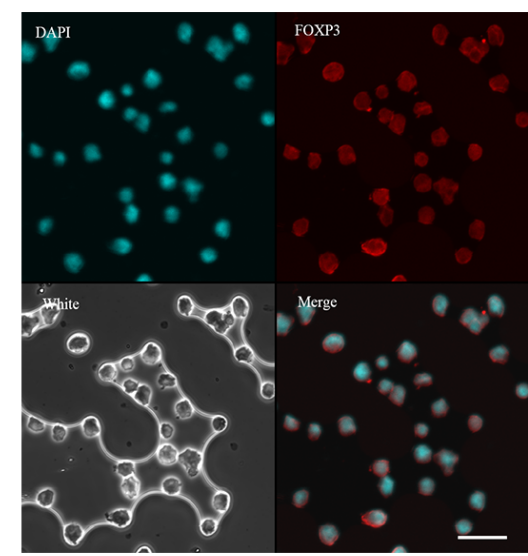

C

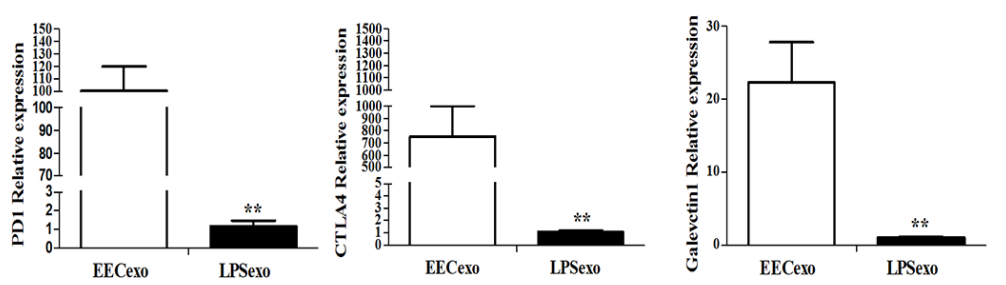

A

B
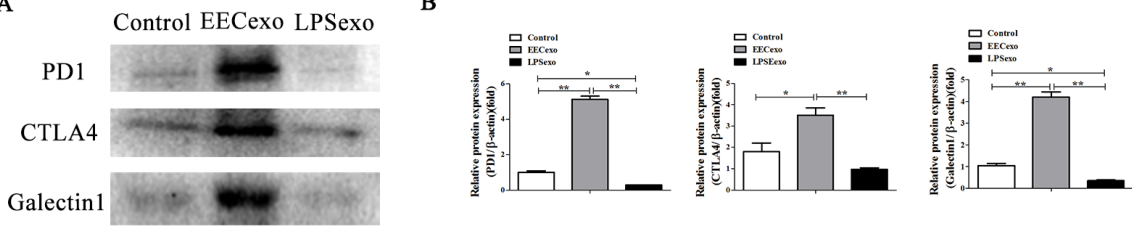

FOXP3

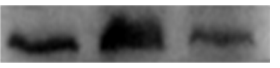

IL17

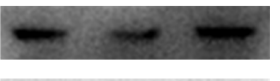

$\beta$-actin
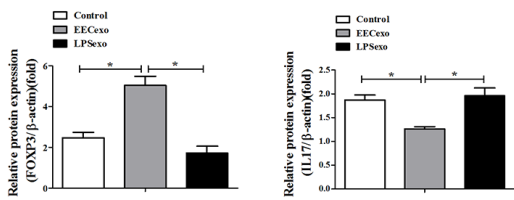


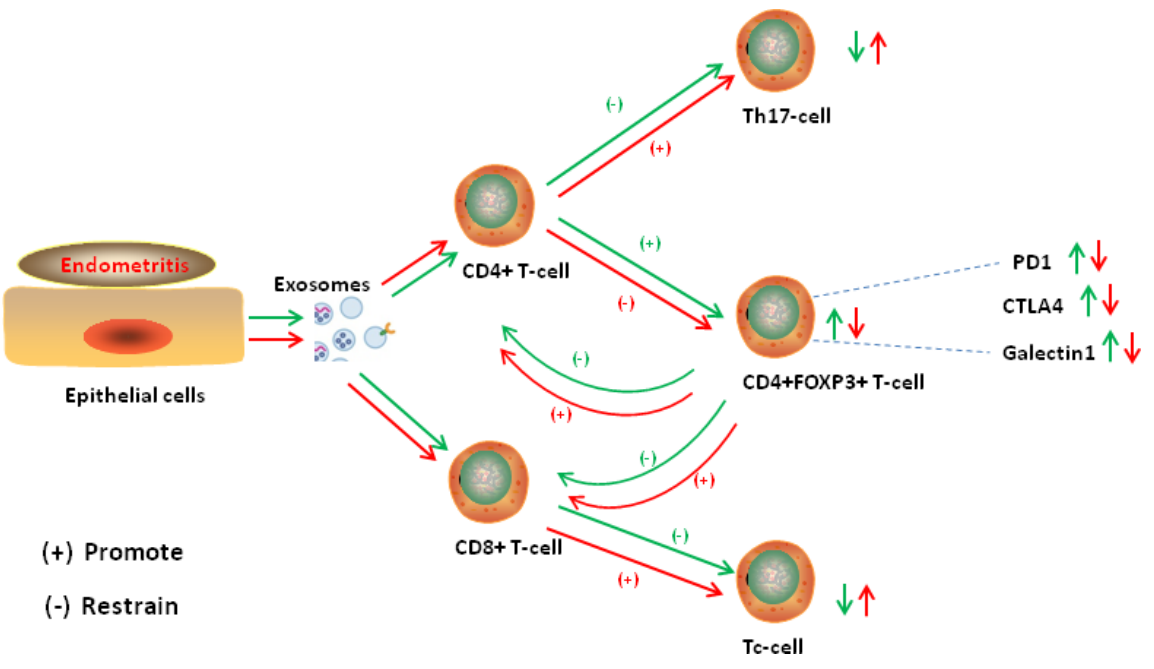

